\title{
ACCURACY OF GRK-2200T AUTO-REFKERATOMETER IN SUBJECTIVE ACCEPTANCE FOR REFRACTIVE ERRORS
}

\author{
Adhikari BN ${ }^{1 *}$, Gautam PS $S^{2}$ Upadhyay $S^{3}$, Prakash UC
}

\section{Affiliation}

1. Consultant, Department of Ophthalmology, Nobel Medical College, Biratnagar

2. Lecturer, Department of Ophthalmology, Nobel Medical College, Biratnagar

3. Resident Doctor, Department of Ophthalmology, Nobel Medical College, Biratnagar

\section{ARTICLE INFO \\ Article History \\ Received : 19 February, 2019 \\ Accepted : 23 April, 2019 \\ Published : 30April, 2019}

(C) Authors retain copyright and grant the journal right of first publication with the work simultaneously licensed under Creative Commons Attribution License CC - BY 4.0 that allows others to share the work with an acknowledgment of the work's authorship and initial publication in this journal.

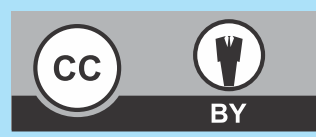

\section{ORA 107}

DOI: http://dx.doi.org/10.3126/bjhs.v4i1.23939

\section{* Corresponding Author}

Dr Bishwa Nath Adhikari Consultant

Department of Ophthalmology

Nobel Medical College Teaching Hospital, Biratnagar, Nepal Email ID: drbishwaa@gmail.com

Orcid ID : https://orcid.org/0000-0003-4569-1936

\section{ABSTRACT}

\section{Introduction}

Globally, the most common cause for diminution of vision is refractive errors and the number of patients with refractive errors is increasing day by day. The Auto-refraction (AR) is quick and patient friendly procedure as compared to retinoscopy and subjective refraction in finding out refractive errors. Hence, the accuracy of Auto-refractometer in terms of subjective acceptance (SA) should be taken into account before prescribing optical correction based on findings of that particular model of Auto-refractometer. So, this study is directed towards analysis of the accuracy of GRK-2200T Auto-refkeratometer in terms of acceptance by comparing findings of AR with that of SC.

\section{Objectives}

The aim of this study was to assess the refractive status of patient's eyes using auto refractometer (GRK-2200T auto-refkerato meter) and to estimate the agreement of it in terms of accuracy in acceptance of subjective correction by the patient.

\section{Methodology}

A hospital based prospective comparative study conducted on 226 eyes of 113 patients who visited out-patient department (OPD) of Ophthalmology at Nobel Medical College and Teaching Hospital (NoMCTH), Biratnagar diagnosed with Myopia, Hyperopia and Astigmatism. Duration of study was 4 months from $2^{\text {nd }}$ October, 2018 to $2^{\text {nd }}$ February, 2019. All data thus collected was subjected to statistical analysis by using SPSS version 22 .

\section{Result}

The mean age of the study subjects was $26.91 \pm 7.79$ years with male to female ratio of 0.47 . When spherical power, cylindrical power and the axis are taken into consideration together, only $13.3 \%$ of the total tested eyes subjectively accepted the AR values unchanged. On subjective correction, $32.7 \%$ of the tested eyes accepted spherical power while $46.5 \%$ accepted cylindrical power and $50.9 \%$ accepted axis of AR unchanged. About $52.2 \%$ of the total eyes examined fall within the deviation of spherical equivalent (SE) of $\pm 0.25 \mathrm{D}$ and up to $67.3 \%$ of them fall within the deviation of $\pm 0.50 D$.

\section{Conclusion}

The auto refraction by GRK-2200T auto-refkeratometer was found to be satisfactory for a preliminary refraction but not satisfactory as substitutes for conventional subjective refraction. However, auto refraction values obtained by GRK-2200T auto-refkeratometer could be important in order to accurately prescribe the cylindrical power as well as its axis than the spherical component.

\section{KEY WORDS}

Refractive errors, auto-refkeratometer, auto-refraction, subjective refraction, spherical equivalent, subjective acceptance 


\section{INTRODUCTION}

Refractive error is the most common disorder of eye worldwide that results in visual impairment and it is estimated that 2.3 billion people in this world suffer from poor vision due to refractive errors. ${ }^{1}$ In most of the cases, decreased vision due to refractive errors, can be corrected by spectacles or contact lens or refractive surgery and it is important to have an accurate measurement of refractive error before application of any such treatment modalities. So, this study is aimed at determining the accuracy of GRK-2200T auto-refkeratometer in subjective acceptance for refractive errors.

\section{METHODOLOGY}

In this cross-sectional study adult patients within the age group of (15-39) years, presenting to the Ophthalmology OPD of Nobel Medical College and Teaching Hospital (NoMCTH), Biratnagar with refractive errors were enrolled for the study after obtaining a written informed consent. Duration of study was 4 months from $2^{\text {nd }}$ October, 2018 to $2^{\text {nd }}$ February, 2019.

A routine ophthalmic examination of both eyes was conducted to rule out any other ocular co-morbidity before patients' enrolment for the study. Those with ocular media opacities and any corneal, lenticular and retinal diseases were excluded and a total of 226 eyes of 113 subjects were evaluated.

Autorefraction was done using a table mount auto refractometer (GRK-2200T auto-refkeratometer). Three values were taken, the average of which was automatically calculated by the machine. This was followed by giving subjective correction, both monocular as well as binocular, until best corrected visual acuity was achieved.

All data thus collected was subjected to statistical analysis by using SPSS version 22 and level of significance was analyzed by chi square test. Relative accuracy of GRK-2200T autorefkeratometer with respect to subjective correction was noted.

\section{RESULTS}

The mean age of the study subjects was $26.91 \pm 7.79$ years with male to female ratio of 0.47 .All of the total eyes ( 226 eyes of 113 subjects) included in this study were within normal limits on anterior segment and posterior segment examinations.

About $52.7 \%$ of the eyes have uncorrected visual acuity of $6 / 9$ and rest have VA of $6 / 12$ or less. Approximately $69 \%$ of the eyes improved to $6 / 6$ on pinhole while $83.2 \%$ of them improved to $6 / 6$ on subjective correction.

Of the total tested eyes, $68.6 \%$ have positive spherical values on AR while only $46 \%$ have the same on subjective correction but about $51.3 \%$ have positive cylindrical values on AR while $72.6 \%$ have the same on subjective correction.

When spherical power, cylindrical power and the axis are taken into consideration together, only $13.3 \%$ of the total tested eyes subjectively accepted the AR values unchanged.

On subjective correction, $32.7 \%$ of the tested eyes accepted spherical power while $46.5 \%$ accepted cylindrical power and $50.9 \%$ accepted axis of AR unchanged.
The patterns of spherical acceptance of AR based on age, sex and uncorrected VA were statistically insignificant with their p-values as $0.072,0.297$ and 0.157 respectively while the pattern of spherical acceptance of AR with respect to types of spherical component (+/-) of the refractive error correction found to be highly significant statistically $(p=0.000)$.

And the patterns of cylinder acceptance of AR based on age and uncorrected VA were statistically insignificant with their $p$-values as 0.858 and 0.349 respectively while with that of sex $(p=0.016)$ and that with respect to types of cylindrical component $(+/-)$ of the refractive error correction $(p=0.000)$ found to be highly significant statistically.

Though the pattern of cylindrical power acceptance on the basis of spherical power acceptance of AR was statistically insignificant $(p=0.337)$, the same with respect to axis acceptance of AR was found statistically highly significant $(p=0.000)$.

In $15.5 \%$ of the tested eyes, the spherical equivalence of values obtained by GRK-2200T auto-refkeratometer exactly matched with that of subjective correction while $52.2 \%$ and up to $67.3 \%$ of the eyes examined fall within the deviation of SE of about $\pm 0.25 \mathrm{D}$ and $\pm 0.50 \mathrm{D}$ respectively. And the correlation of SE of AR with that of SC was found to be highly significant with $<0.001$ level of significance ( 2 tailed).

Table 1: Gender distribution of the patients
\begin{tabular}{|c|c|c|}
\hline Gender & Frequency (No.) & Percentage (\%) \\
\hline Male & 72 & 31.9 \\
\hline Female & 154 & 68.1 \\
\hline Total & 226 & 100.0 \\
\hline
\end{tabular}

Table 2: Uncorrected Visual Acuity
\begin{tabular}{|c|c|c|}
\hline UCVA & Frequency (No.) & Percent (\%) \\
\hline $6 / 6$ & 1 & 0.4 \\
\hline $6 / 9$ & 119 & 52.7 \\
\hline $6 / 12$ & 37 & 16.4 \\
\hline $6 / 18$ & 17 & 7.5 \\
\hline $6 / 24$ & 17 & 7.5 \\
\hline $6 / 36$ & 11 & 4.9 \\
\hline $6 / 60$ & 13 & 5.8 \\
\hline $5 / 60$ & 9 & 4.0 \\
\hline $4 / 60$ & 1 & 0.4 \\
\hline $3 / 60$ & 1 & 0.4 \\
\hline Total & 226 & 100.0 \\
\hline
\end{tabular}

Table 3: Best Corrected Visual Acuity
\begin{tabular}{|c|c|c|}
\hline BCVA & Frequency (No.) & Percent (\%) \\
\hline $6 / 6$ & 188 & 83.2 \\
\hline $6 / 9$ & 30 & 13.3 \\
\hline $6 / 18$ & 5 & 2.2 \\
\hline $6 / 36$ & 2 & 0.9 \\
\hline $6 / 60$ & 1 & 0.4 \\
\hline Total & 226 & 100.0 \\
\hline
\end{tabular}

Table 4: Spherical Power Acceptance of Auto-
refkeratometer
\begin{tabular}{|c|c|c|}
\hline $\begin{array}{c}\text { Spherical Power } \\
\text { Acceptance }\end{array}$ & Frequency (No.) & Percent (\%) \\
\hline Accepted & 74 & 32.7 \\
\hline Not accepted & 152 & 67.3 \\
\hline Total & 226 & 100.0 \\
\hline
\end{tabular}


Table 5: Cylindrical Power Acceptance of Auto-

refkeratometer

\begin{tabular}{|c|c|c|}
\hline $\begin{array}{c}\text { Cylindrical Power } \\
\text { Acceptance }\end{array}$ & Frequency (No.) & Percent (\%) \\
\hline Accepted & 105 & 46.5 \\
\hline Not accepted & 121 & 53.5 \\
\hline Total & 226 & 100.0 \\
\hline
\end{tabular}

Table 6: Cylindrical Axis Acceptance of Auto-

refkeratometer

\begin{tabular}{|c|c|c|}
\hline $\begin{array}{c}\text { Cylindrical Axis } \\
\text { Acceptance }\end{array}$ & Frequency (No.) & Percent (\%) \\
\hline Accepted & 115 & 50.9 \\
\hline Not accepted & 111 & 49.1 \\
\hline Total & 226 & 100.0 \\
\hline
\end{tabular}

Table 7: Pattern of Cylindrical Power Acceptance on the Basis of Spherical Power Acceptance

\begin{tabular}{|c|c|c|c|}
\hline \multirow{2}{*}{$\begin{array}{c}\text { Spherical } \\
\text { Power } \\
\text { Acceptance }\end{array}$} & \multicolumn{3}{|c|}{ Cylindrical Power Acceptance } \\
\cline { 2 - 4 } & Accepted & Not accepted & Total \\
\hline Accepted & 31 & 43 & 74 \\
\hline Not accepted & 74 & 78 & 152 \\
\hline Total & 105 & 121 & 226 \\
\hline
\end{tabular}

Table 8: Pattern of Cylindrical Axis Acceptance on the Basis of Cylindrical Power Acceptance

\begin{tabular}{|c|c|c|c|}
\hline \multirow{2}{*}{$\begin{array}{c}\text { Cylindrical } \\
\text { Axis } \\
\text { Acceptance }\end{array}$} & \multicolumn{3}{|c|}{ Cylindrical Power Acceptance } \\
\cline { 2 - 4 } & Accepted & Not accepted & Total \\
\hline Accepted & 100 & 15 & 115 \\
\hline Not accepted & 5 & 106 & 111 \\
\hline Total & 105 & 121 & 226 \\
\hline
\end{tabular}

Table 9: Deviation of Spherical Equivalent of Autorefkeratometer from Subjective Correction

\begin{tabular}{|c|c|c|}
\hline Deviation of SE (Diaptre) & Frequency (No.) & Percentage (\%) \\
\hline .00 & 35 & 15.5 \\
\hline .05 & 1 & .4 \\
\hline .12 & 7 & 3.1 \\
\hline .13 & 17 & 7.5 \\
\hline .25 & 58 & 25.7 \\
\hline .37 & 2 & .9 \\
\hline .38 & 7 & 3.1 \\
\hline .50 & 25 & 11.1 \\
\hline .62 & 2 & .9 \\
\hline .63 & 6 & 2.7 \\
\hline .75 & 10 & 4.4 \\
\hline .88 & 3 & 1.3 \\
\hline 1.00 & 8 & 3.5 \\
\hline 1.12 & 1 & .4 \\
\hline 1.13 & 1 & .4 \\
\hline 1.25 & 5 & 2.2 \\
\hline 1.38 & 1 & .4 \\
\hline 1.50 & 4 & 1.8 \\
\hline 1.63 & 3 & 1.3 \\
\hline 1.75 & 6 & 2.7 \\
\hline 1.88 & 3 & 1.3 \\
\hline 2.00 & 5 & 2.2 \\
\hline 2.13 & 2 & .9 \\
\hline 2.38 & 3 & 1.3 \\
\hline 2.88 & 2 & .9 \\
\hline 3.00 & 2 & .9 \\
\hline 3.38 & 1 & .4 \\
\hline 3.50 & 2 & .9 \\
\hline 3.87 & 1 & .4 \\
\hline 4.00 & 1 & .4 \\
\hline 6.00 & 2 & .9 \\
\hline Total & 226 & 100.0 \\
\hline
\end{tabular}

Table 10: Acceptance of all components of Autorefkeratometer findings with Subjective Refraction

\begin{tabular}{|c|c|c|}
\hline $\begin{array}{c}\text { Spherical power, Cylindrical } \\
\text { Power and Axis Acceptance }\end{array}$ & $\begin{array}{c}\text { Frequency } \\
\text { (No.) }\end{array}$ & Percentage (\%) \\
\hline Accepted & 30 & 13.3 \\
\hline Not accepted & 196 & 86.7 \\
\hline Total & 226 & 100.0 \\
\hline
\end{tabular}

\section{DISCUSSIONS}

As this study was aimed at finding out the relative accuracy of GRK 2200T auto-refkeratometer to subjective acceptance for refractive error, when spherical power, cylindrical power and the axis are taken into consideration together, only $13.3 \%$ of the total tested eyes subjectively accepted the AR values unchanged.

A study conducted by Jorge et al. in 192 right eyes from 192 healthy young adults in Portugal and Spain showed that when spherical power, cylindrical power and the axis are taken into consideration together, only $21.9 \%$ satisfy this stringent criterion ${ }^{2}$ when we compare Autorefraction with subjective refraction while our study showed only $13.3 \%$ of the tested eyes accepted the same.

In a study by Yee Fong Choong et al in the paediatric age group, AR showed a minus over correction in most patients. ${ }^{3}$ But another clinical study done by EA Mallen, JS Wolffsohn, B Gilmartin and S. Tsujimura in UK in 200 eyes of 100 subjects suggested that the SRW-5000 auto refractor read slightly more plus than subjective refraction and it was found to be highly valid (accurate) compared to subjective refraction over the prescription range of +6.50 to $-15.00 \mathrm{D}$. ${ }^{4}$ But our study showed plus over correction for spherical power with $68.6 \%$ having positive spherical values on $A R$ while only $46 \%$ have the same on subjective correction and plus under correction for cylindrical power with about $51.3 \%$ having positive cylindrical values on AR while $72.6 \%$ have the same on subjective correction.

In the study by Jorge et al, $44.3 \%$ accepted the sphere power, 89.6\% accepted cylindrical power and 55.2\% accepted cylinder axis obtained by AR. Yet another clinical study by Goss DA and Grosvenor T in USA published a closer agreement between Auto refraction and other refraction methods regarding the cylinder component, whereas poorer agreement was reported for the sphere component. ${ }^{5}$ Similarly, our study revealed that about $32.7 \%$ of the eyes accepted spherical power while $46.5 \%$ accepted cylindrical power and $50.9 \%$ accepted axis of AR unchanged, showing closer agreement for cylindrical power as well as axis than spherical component.

In a study by Jorge et al, the results obtained for the value of the spherical equivalent showed that the auto refractor values were more negative in myopia and less positive in hypermetropia than subjective refraction. These results were similar to those of Bullimore et $\mathrm{al}^{6}$ and Zadnik et al ${ }^{7}$ for the auto refractor and subjective refraction values. A multitude of other studies in which different models of 
autorefractor were evaluated, also showed the same tendency of the autorefractor to underestimate the value of the refractive error in relation to the other methods. But our study found that the mean SE with AR was $0.86 \pm 1.47$ and subjectively, it was $0.68 \pm 1.12$ showing the tendency of $A R$ to overestimate the values of the refractive errors as compared to subjective refraction.

\section{CONCLUSION}

From the above observation, analysis and discussion, it can be concluded that autorefraction by GRK-2200T Autorefkeratometer was satisfactory for a preliminary refraction but not satisfactory as substitutes for conventional subjective refraction.

\section{RECOMMENDATIONS}

The autorefraction values obtained by GRK-2200T Autorefkeratometer could be more important in order to accurately prescribe the cylindrical axis as well as its power than the spherical component.

\section{LIMITATIONS OF THE STUDY}

In this study, refraction was carried out solely without cycloplegia so, comparison of theaccuracy of dry refraction with that of cycloplegic refraction in subjective acceptance couldn't be analyzed.

\section{ACKNOWLEDGEMENT}

We are very thankful to our expert refractionist and supporting staff in auto-refraction and data collection.

\section{CONFLICT OFINTEREST}

None

\section{FINANCIAL DISCLOSURE}

None

5. Goss DA, Grosvenor T. Reliability of refraction--a literature review. Journal of the American Optometric Association 1996;67(10):61930.PMID: 8942135

6. Bullimore MA, Fusaro RE, Adams CW. The repeatability of automated and clinician refraction. Optometry and vision science: official publication of the American Academy of Optometry. 1998;75(8):617-22.PMID: 9734807

7. Zadnik K, Mutti DO, Adams AJ. The repeatability of measurement of the ocular components. Investigative ophthalmology \& visual science. 1992;33(7):2325-33.PMID:1607244

4. Mallen EA, Wolffsohn JS, Gilmartin B, Tsujimura S. Clinical evaluation of the Shin-Nippon SRW-5000 autorefractor in adults. Ophthalmic and Physiological Optics. 2001;21(2): 101-7.PMID: 11261343 